(C) American Chemical Society, J. Phys. Chem. B, Kim et al, jp048582k Supporting Info Page S1

\title{
Tailoring the Pore Structure of SBA-16 Silica Molecular Sieve through the Use of Copolymer Blends and Control of Synthesis Temperature and Time
}

\author{
Tae-Wan Kim, ${ }^{a}$ Ryong Ryoo, ${ }^{a *}$ Michal Kruk, ${ }^{\text {b,c }}$ Kamil Gierszal, ${ }^{\text {b }}$ Mietek Jaroniec, ${ }^{\text {b* }}$ \\ Satoshi Kamiyad and Osamu Terasaki ${ }^{\text {d,e }}$
}

${ }^{a}$ National Creative Research Initiative Center for Functional Nanomaterials, and Department of Chemistry (School of Molecular Science-BK21), Korea Advanced Institute of Science and Technology, Daejeon, 305-701, Korea

${ }^{\mathrm{b}}$ Department of Chemistry, Kent State University, Kent, OH 44242, USA

${ }^{\text {c }}$ Current address: Department of Chemistry, Carnegie Mellon University, Pittsburgh, PA 15213, USA

${ }^{d}$ Department of Physics, Graduate School of Science and Center for Interdisciplinary Research, Tohoku University, Sendai 980-8578, Japan

${ }^{\text {e }}$ Current address: Arrhenius Laboratory, Stockholm University, 10691 Stockholm, Sweden

* Correspondence should be addressed to Professor R. Ryoo (E-mail: rryoo@kaist.ac.kr) and Professor M. Jaroniec (Phone: 330-672-3790; Fax: 330-672-3816; E-mail: jaroniec@kent.edu). 
(C) American Chemical Society, J. Phys. Chem. B, Kim et al, jp048582k Supporting Info Page S2

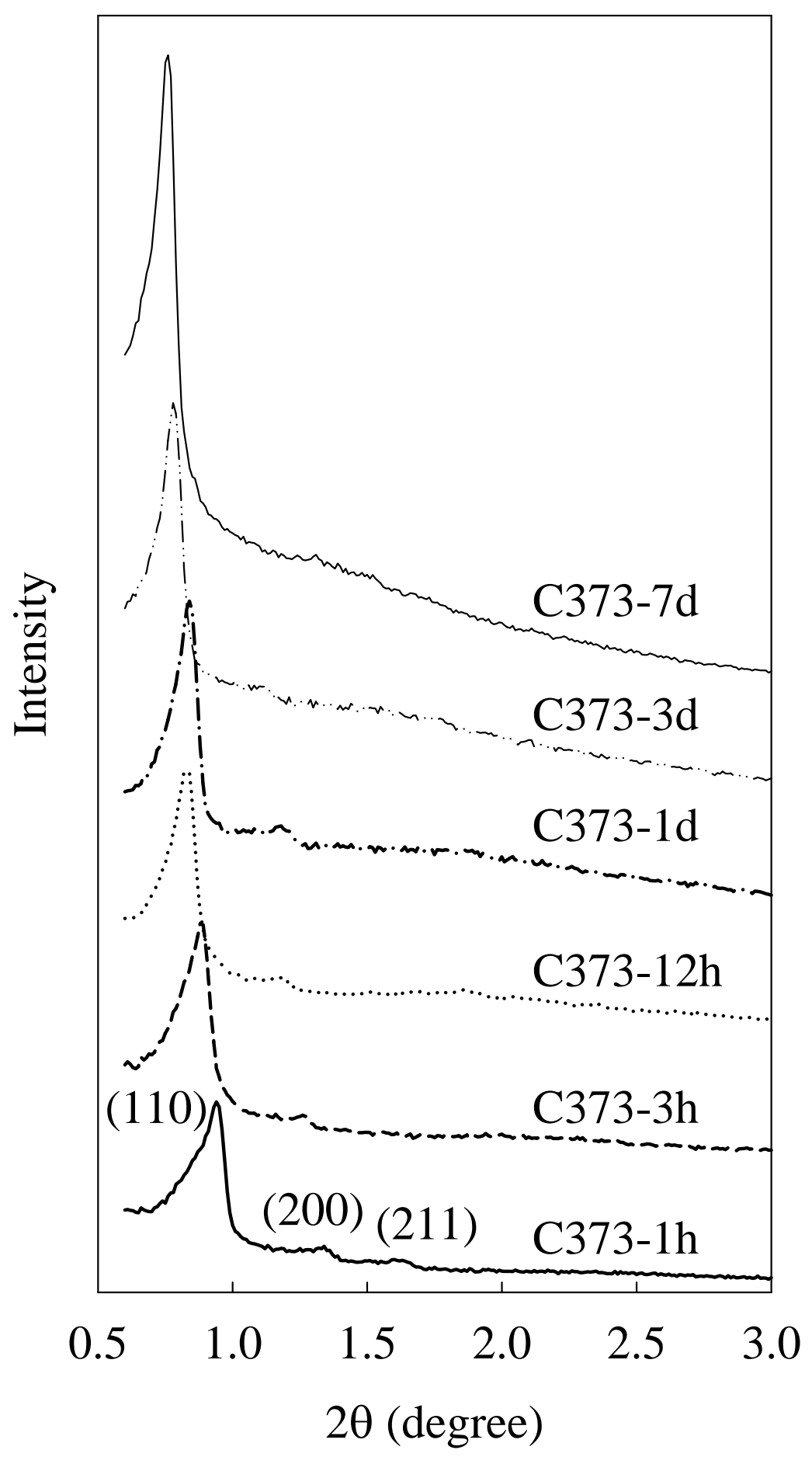

Supporting Figure 1S. XRD patterns for SBA-16 silicas synthesized using a mixture of Pluronic F127 and P123 with average composition of $\mathrm{EO}_{80} \mathrm{PO}_{70} \mathrm{EO}_{80}$ in a two-step synthesis involving the heating at $373 \mathrm{~K}$ for different periods of time. 
(C) American Chemical Society, J. Phys. Chem. B, Kim et al, jp048582k Supporting Info Page S3

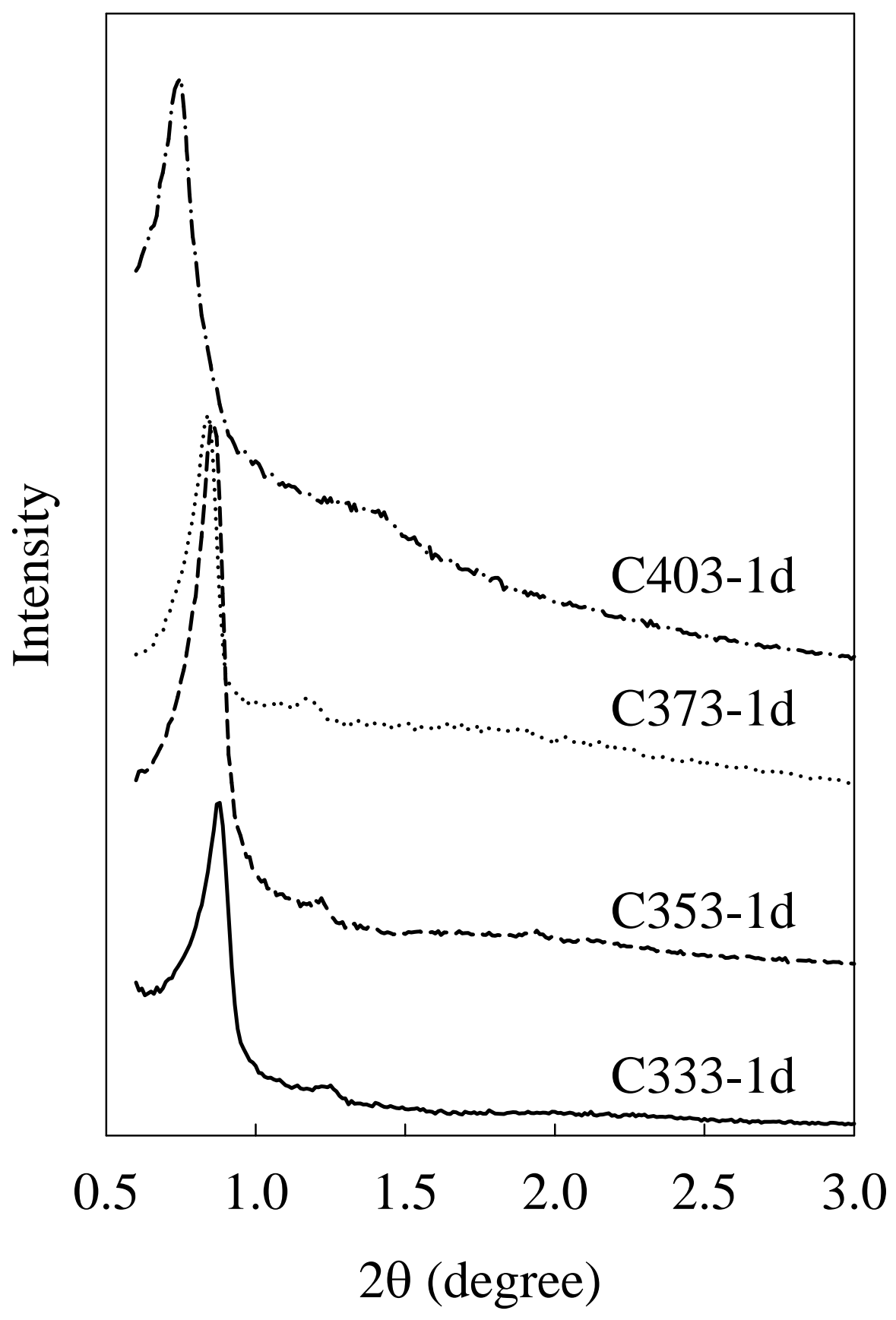

Supporting Figure 2S. XRD patterns for SBA-16 silicas synthesized using a mixture of Pluronic F127 and P123 with average composition of $\mathrm{EO}_{80} \mathrm{PO}_{70} \mathrm{EO}_{80}$ in a two-step synthesis involving the heating at different temperatures. 
(C) American Chemical Society, J. Phys. Chem. B, Kim et al, jp048582k Supporting Info Page S4

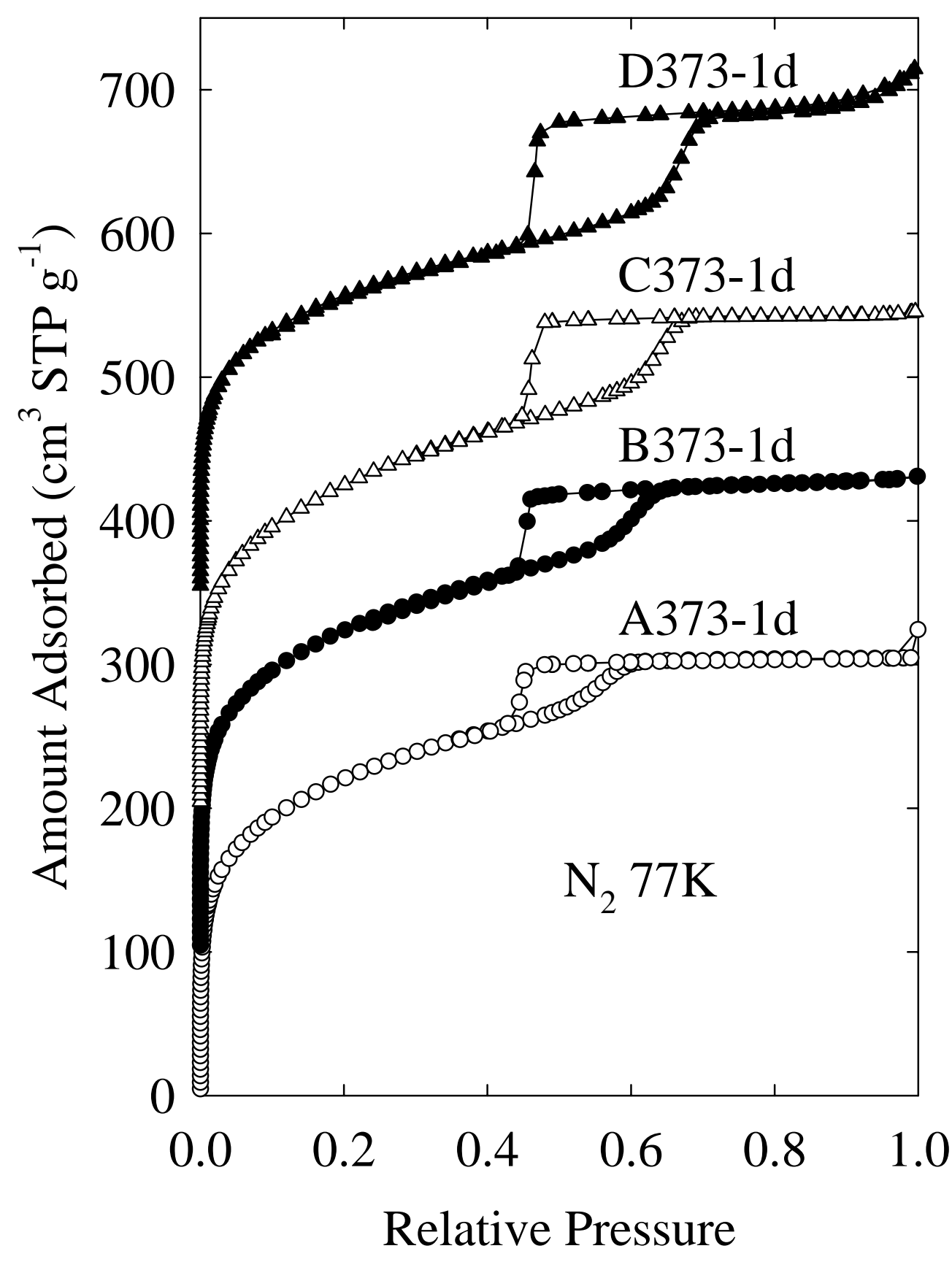

Supporting Figure 3S. Nitrogen adsorption isotherms for SBA-16 silicas synthesized using Pluronic F127 and mixtures of Pluronic F127 and P123 with different molar ratios. The isotherms for samples B373-1d, C373-1d and D373-1d were offset vertically by 100, 200, and $350 \mathrm{~cm}^{3} \mathrm{STP} \mathrm{g}^{-1}$, respectively. 
(C) American Chemical Society, J. Phys. Chem. B, Kim et al, jp048582k Supporting Info Page S5

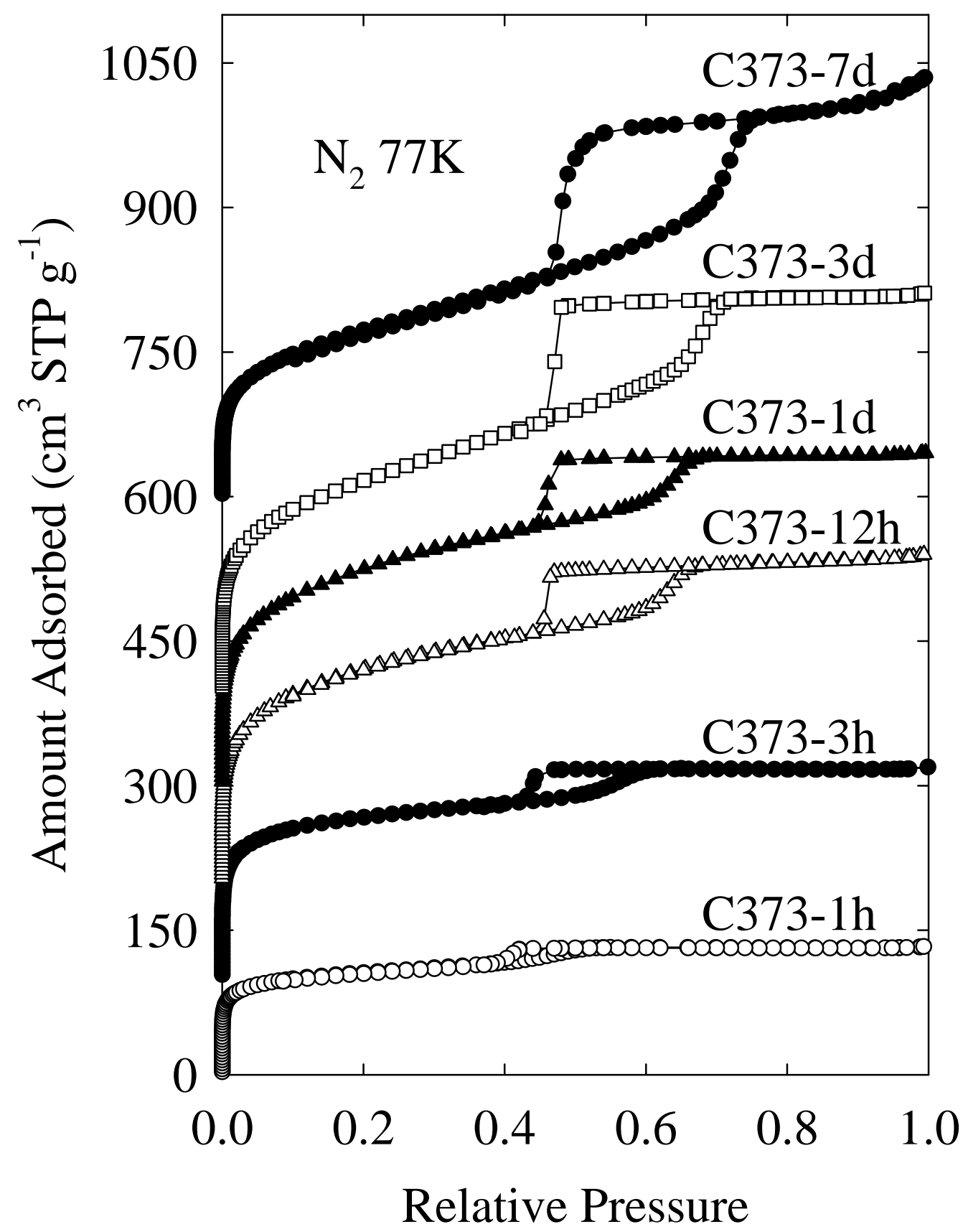

Supporting Figure 4S. Nitrogen adsorption isotherms for SBA-16 silicas synthesized using a mixture of Pluronic F127 and P123 with average composition of $\mathrm{EO}_{80} \mathrm{PO}_{70} \mathrm{EO}_{80}$ in a two-step synthesis involving the heating at $373 \mathrm{~K}$ for different periods of time. The isotherms for samples C373-3d, C373-12h, C373-1d, C373-3d and C373-7d were offset vertically by 100, 200, 300, 400 and $600 \mathrm{~cm}^{3} \mathrm{STP} \mathrm{g}^{-1}$, respectively. 
(C) American Chemical Society, J. Phys. Chem. B, Kim et al, jp048582k Supporting Info Page S6

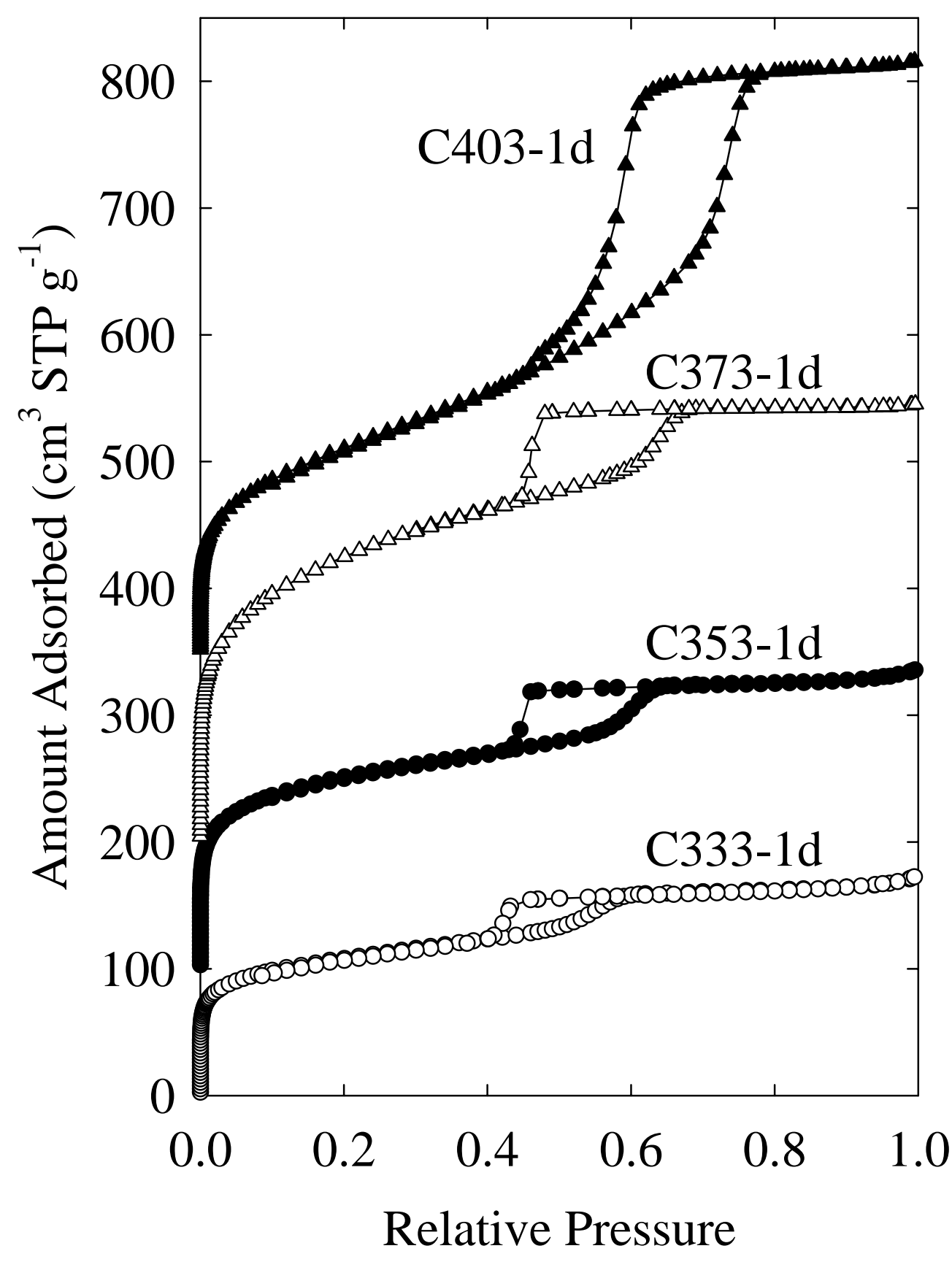

Supporting Figure 5S. Nitrogen adsorption isotherms for SBA-16 silicas synthesized using a mixture of Pluronic F127 and P123 with average composition of $\mathrm{EO}_{80} \mathrm{PO}_{70} \mathrm{EO}_{80}$ in a two-step synthesis involving the heating at different temperatures. The isotherms for samples C353-1d, C373-1d, and C403-1d were offset vertically by 100, 200 and $350 \mathrm{~cm}^{3} \mathrm{STP} \mathrm{g}^{-1}$, respectively. 
(C) American Chemical Society, J. Phys. Chem. B, Kim et al, jp048582k Supporting Info Page S7

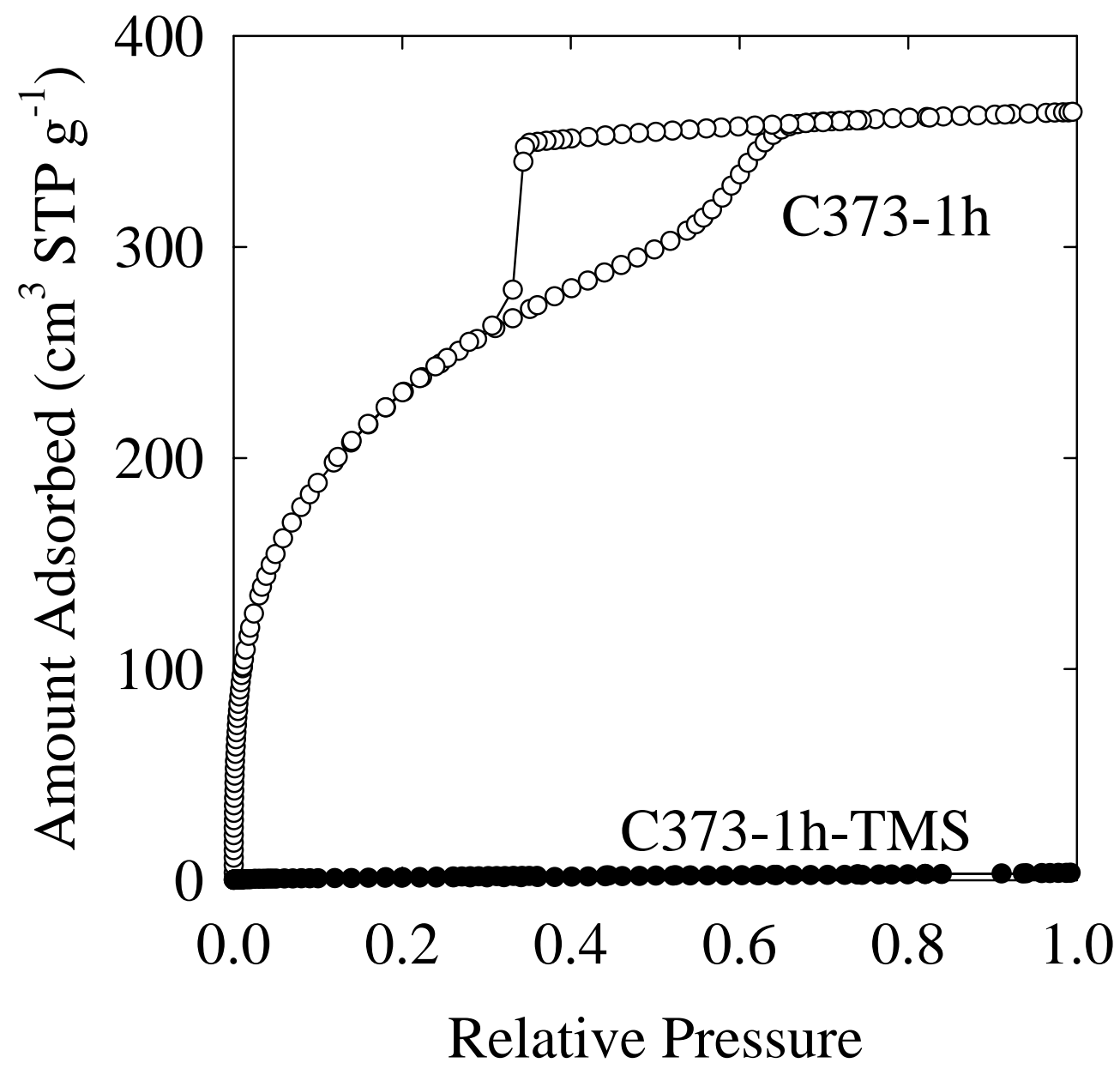

Supporting Figure 6S. Argon adsorption isotherms for SBA-16 sample C373-1h, unmodified and modified with trimethylsilyl ligands. 
(C) American Chemical Society, J. Phys. Chem. B, Kim et al, jp048582k Supporting Info Page S8

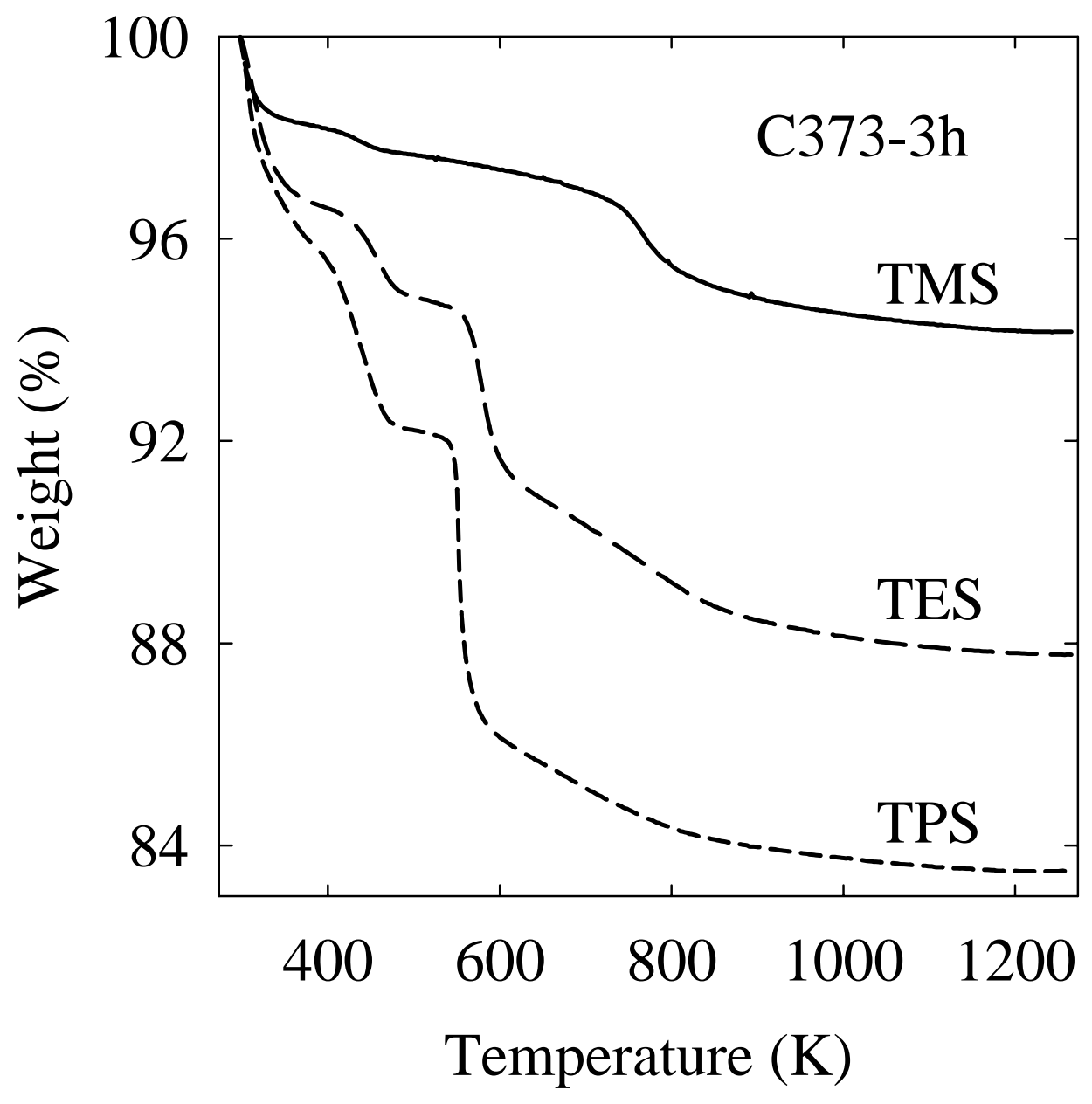

Supporting Figure 7S. Weight change curves recorded under air atmosphere for SBA-16 sample C373-3h modified with trimethylsilyl, triethylsilyl and tripropylsilyl ligands. 
(C) American Chemical Society, J. Phys. Chem. B, Kim et al, jp048582k Supporting Info Page S9

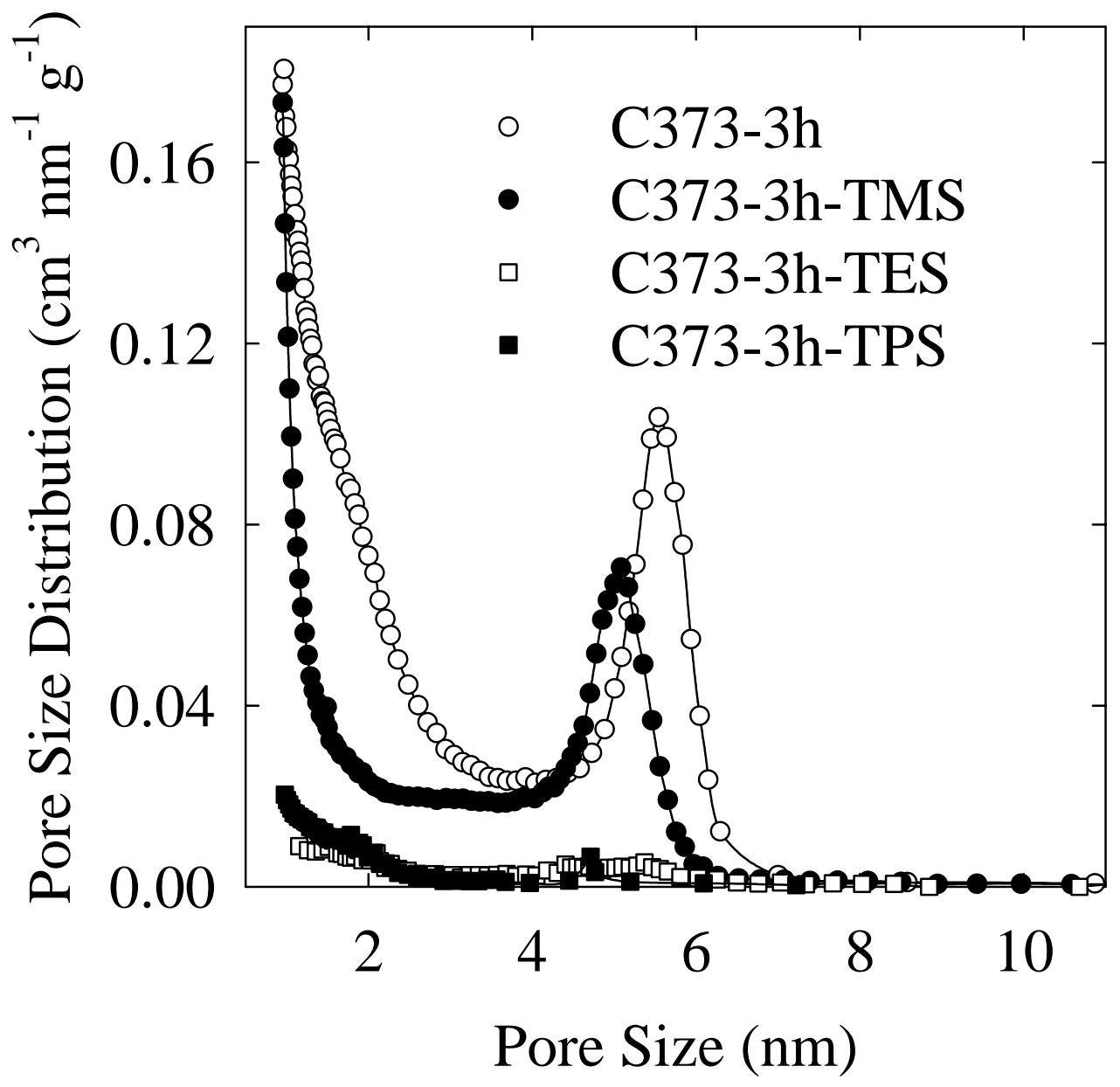

Supporting Figure 8S. Pore size distributions calculated from argon adsorption isotherms for SBA-16 sample C373-3h, unmodified and modified with trimethylsilyl, triethylsilyl and tripropylsilyl ligands. 
(C) American Chemical Society, J. Phys. Chem. B, Kim et al, jp048582k Supporting Info Page S10

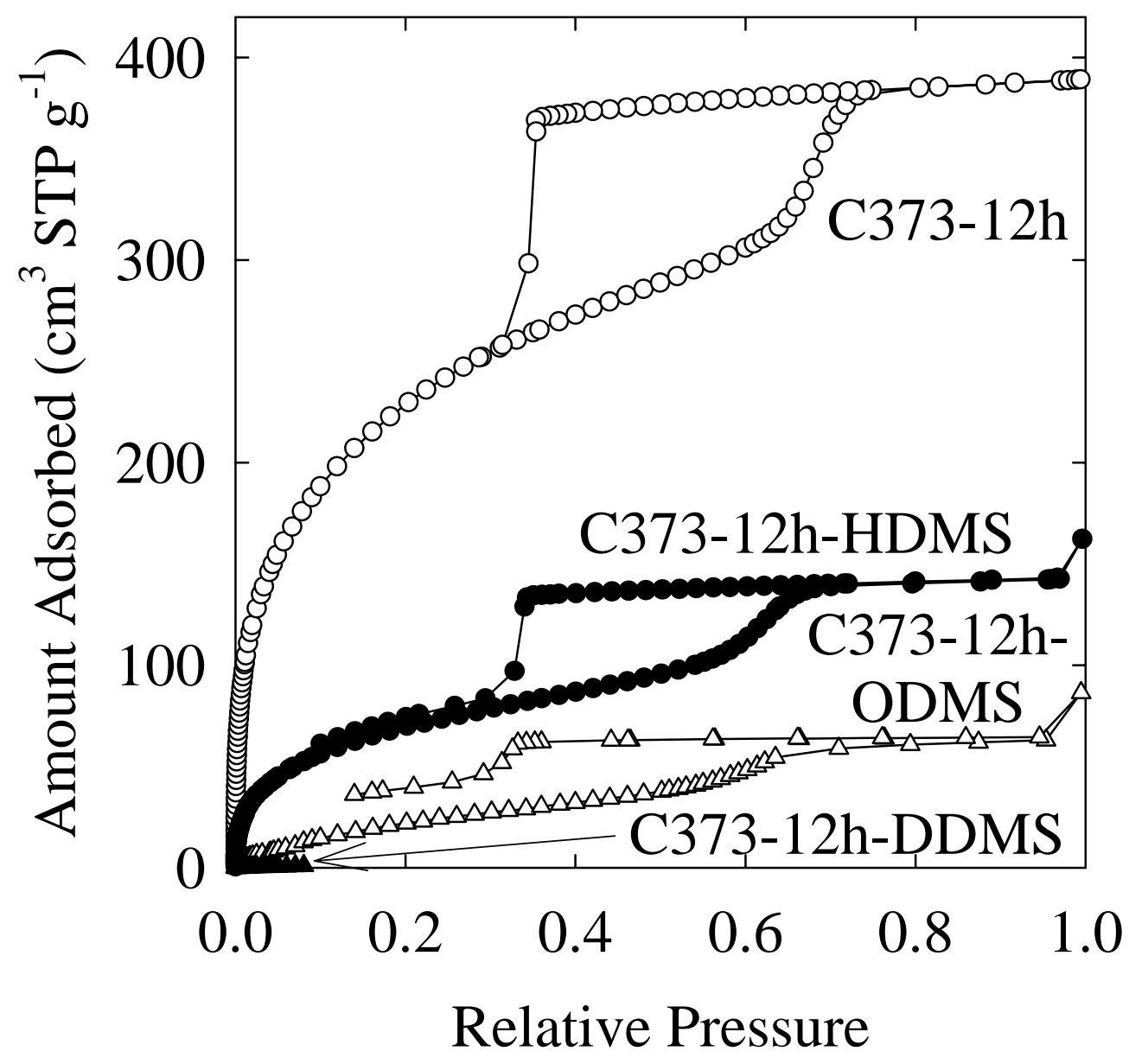

Supporting Figure 9S. Argon adsorption isotherms for SBA-16 sample C373-12h, unmodified and modified with hexyldimethylsilyl, octyldimethylsilyl and decyldimethylsilyl ligands. 
(c) American Chemical Society, J. Phys. Chem. B, Kim et al, jp048582k Supporting Info Page S11

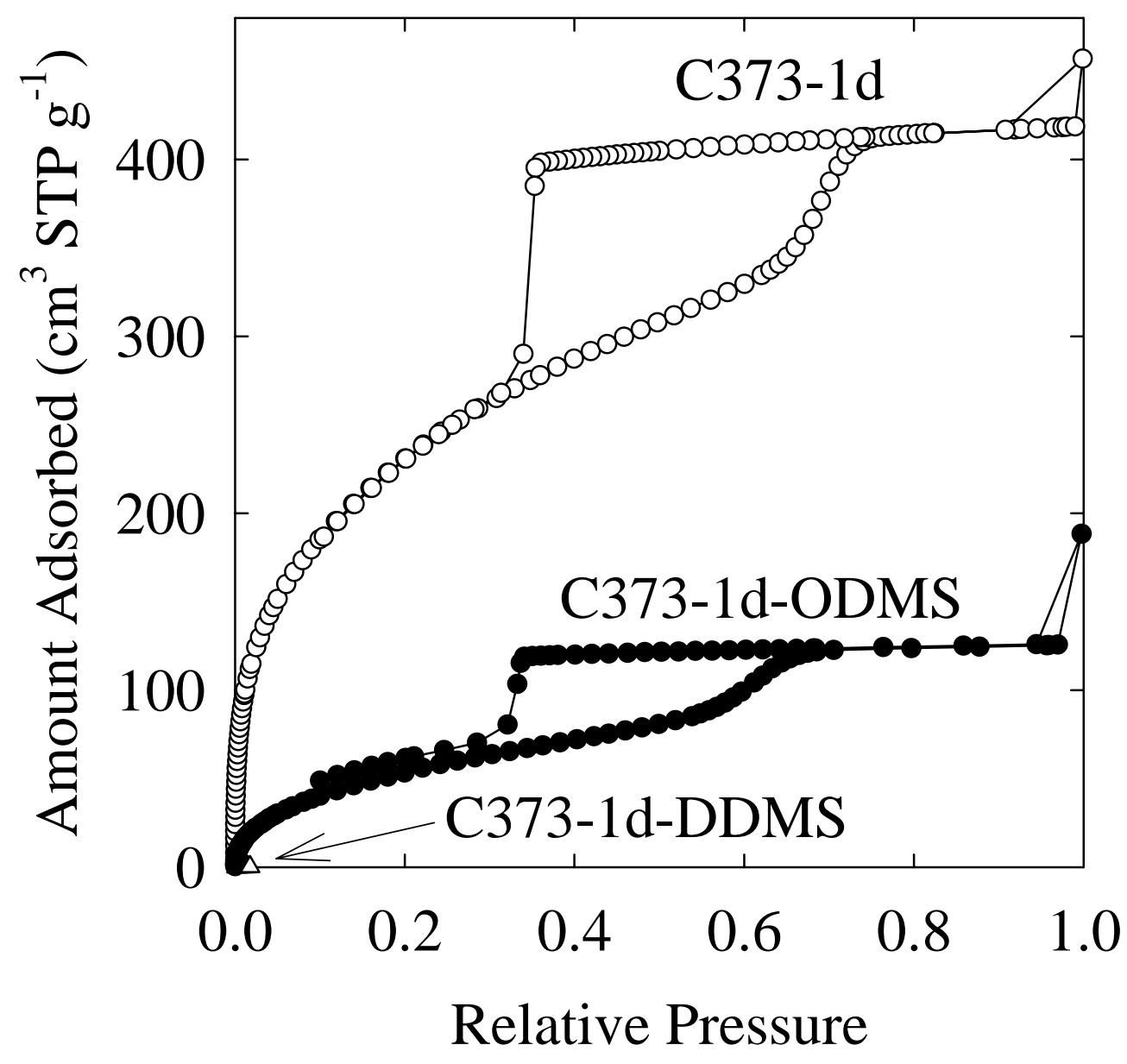

Supporting Figure 10S. Argon adsorption isotherms for SBA-16 sample C373-1d, unmodified and modified with octyldimethylsilyl and decyldimethylsilyl ligands. 
(C) American Chemical Society, J. Phys. Chem. B, Kim et al, jp048582k Supporting Info Page S12

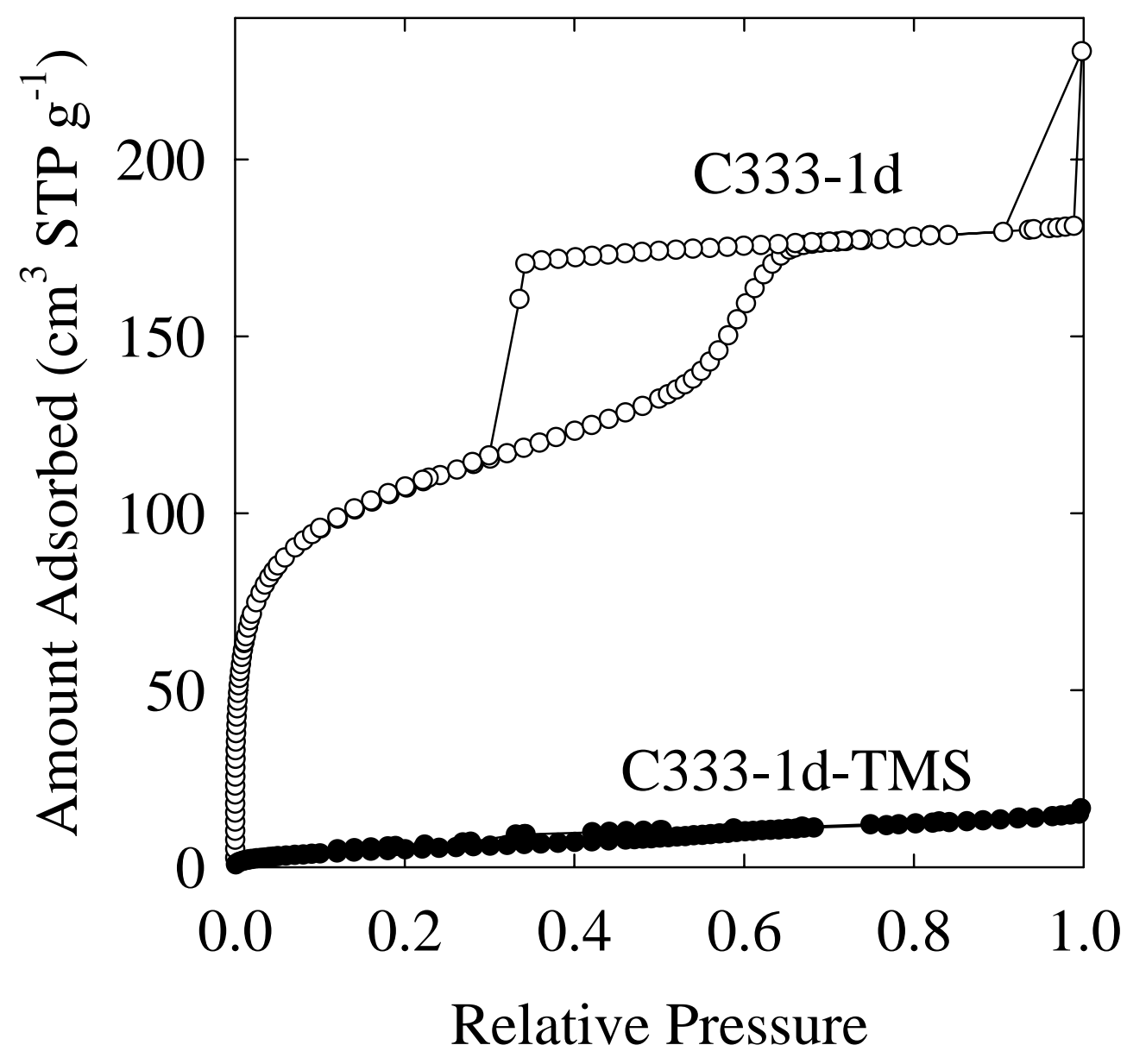

Supporting Figure 11S. Argon adsorption isotherms for SBA-16 sample C333-1d, unmodified and modified with trimethylsilyl ligands. 
(C) American Chemical Society, J. Phys. Chem. B, Kim et al, jp048582k Supporting Info Page S13

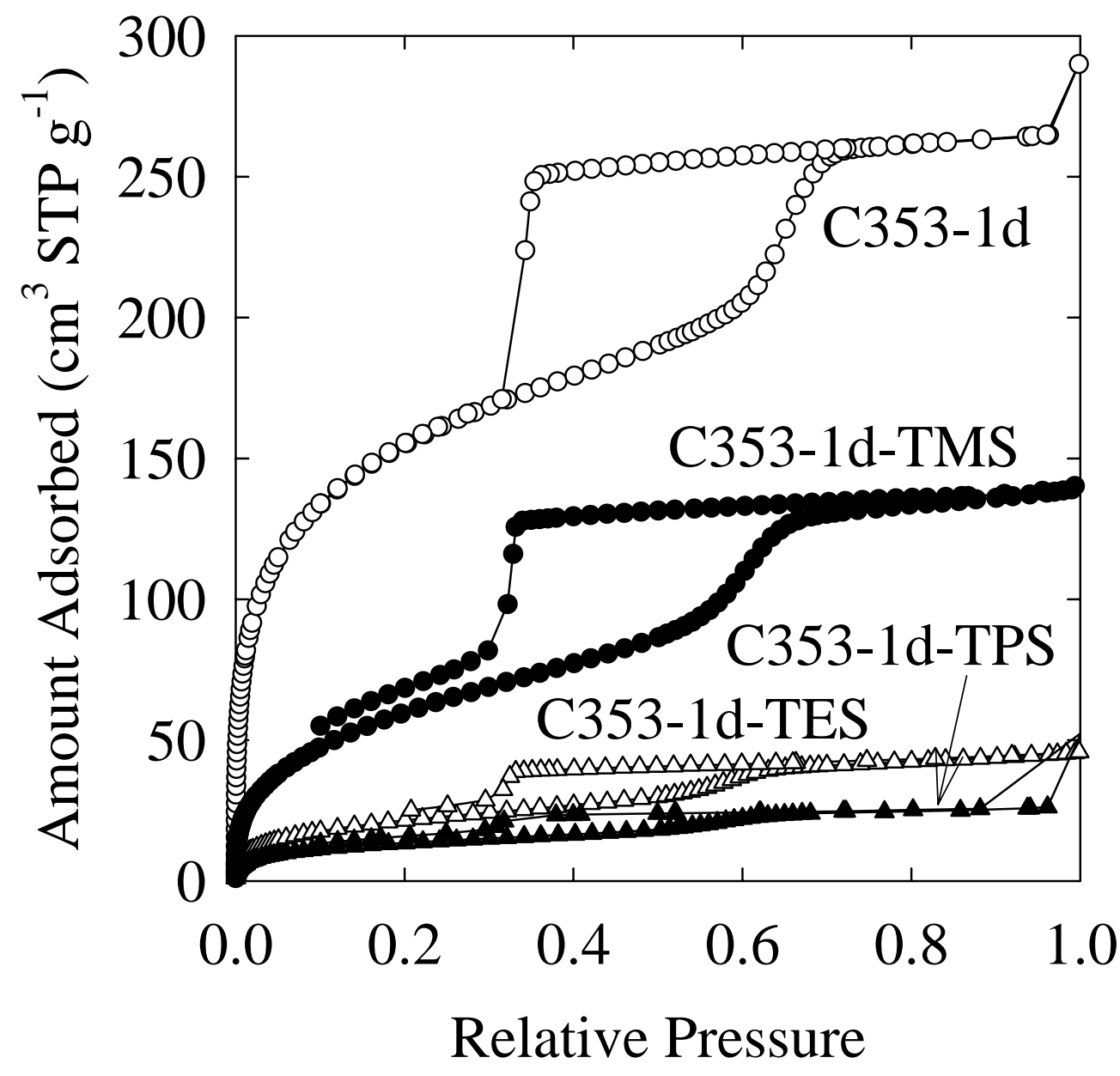

Supporting Figure 12S. Argon adsorption isotherms for SBA-16 sample C353-1d, unmodified and modified with trimethylsilyl, triethylsilyl and tripropylsilyl ligands. 
(c) American Chemical Society, J. Phys. Chem. B, Kim et al, jp048582k Supporting Info Page S14

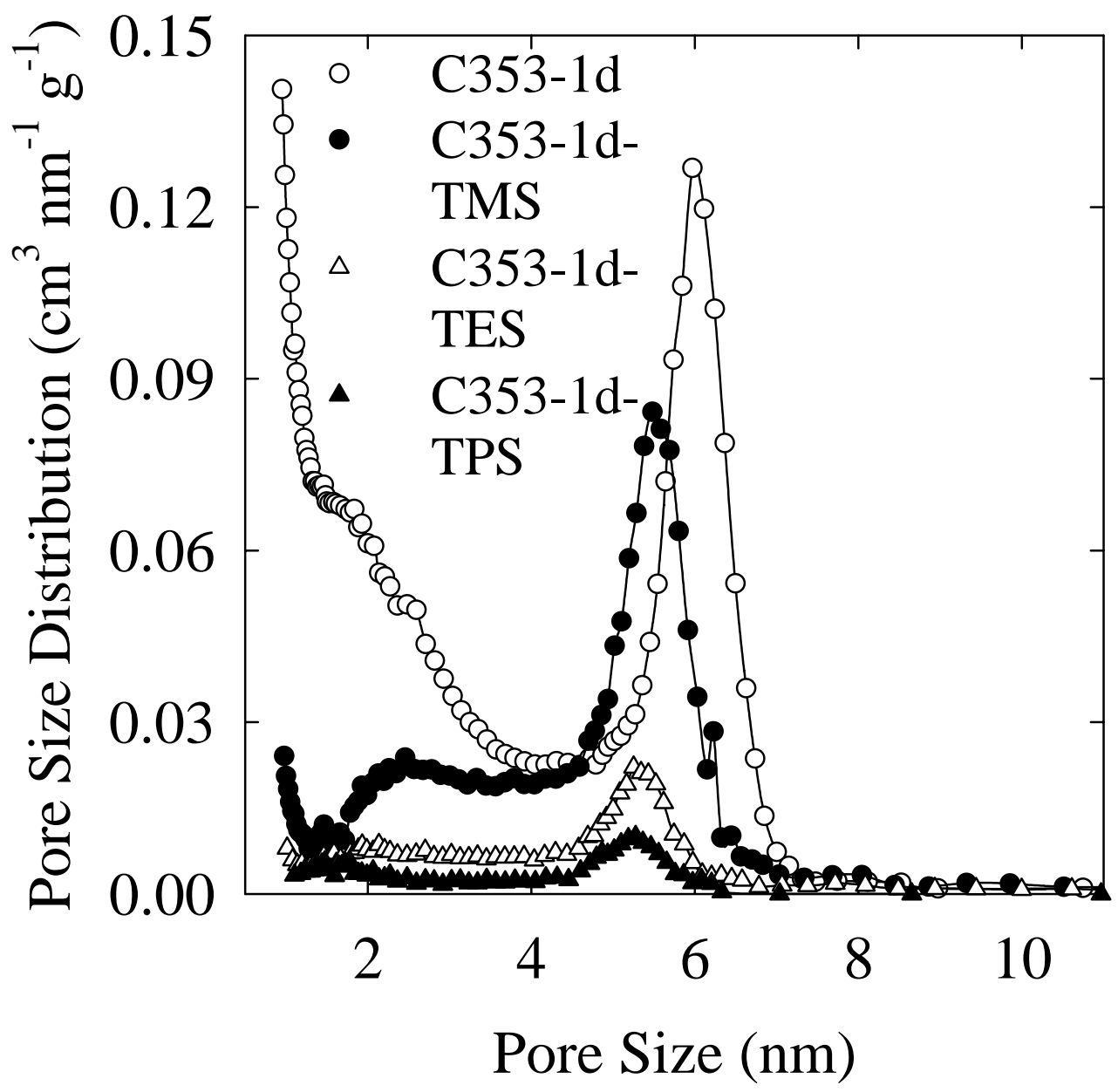

Supporting Figure 13S. Pore size distributions calculated from argon adsorption isotherms for SBA-16 sample C353-1d, unmodified and modified with trimethylsilyl, triethylsilyl and tripropylsilyl ligands. 
(C) American Chemical Society, J. Phys. Chem. B, Kim et al, jp048582k Supporting Info Page S15

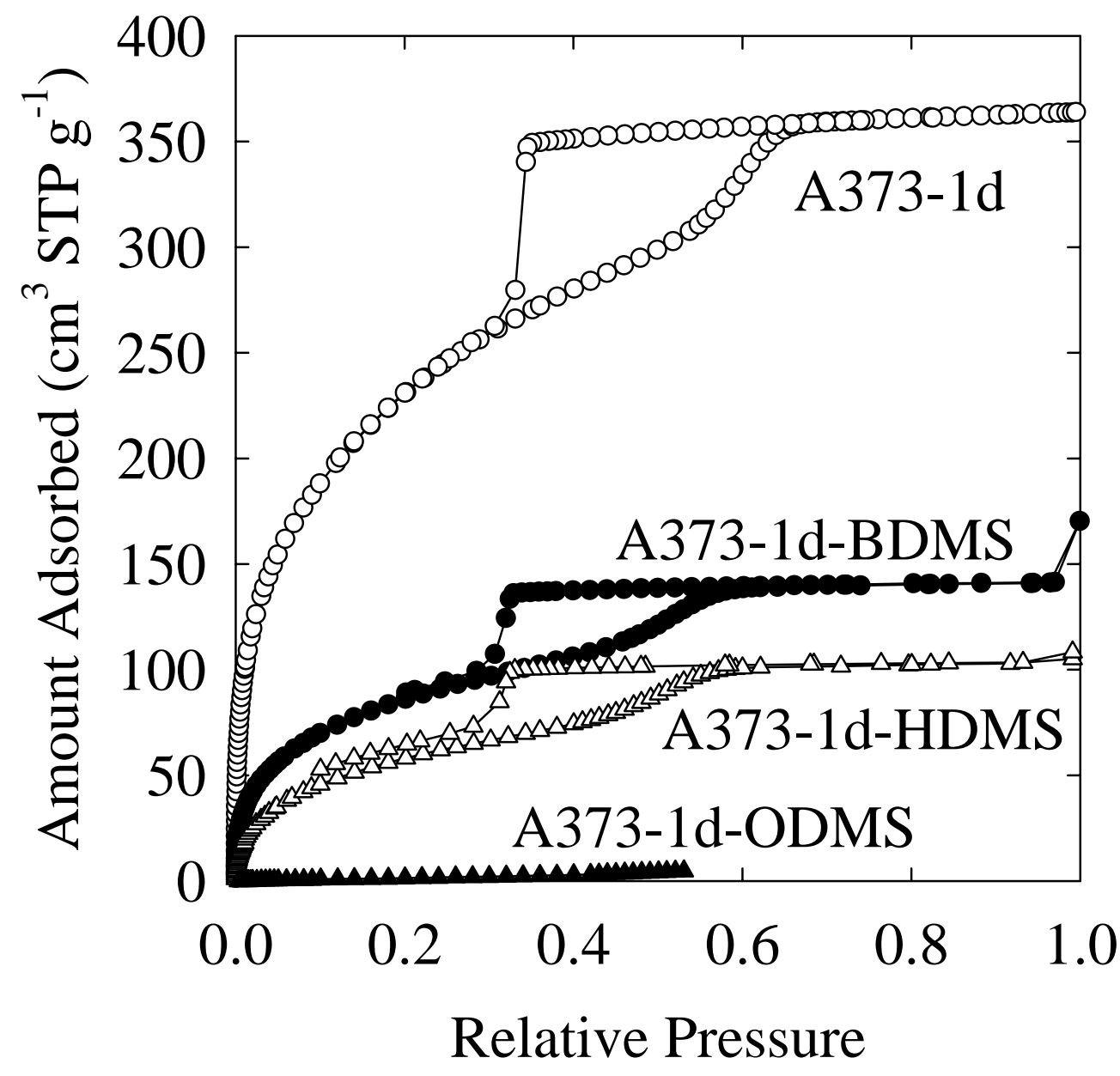

Supporting Figure 14S. Argon adsorption isotherms for SBA-16 sample A373-1d, unmodified and modified with butyldimethylsilyl, hexyldimethylsilyl and octyldimethylsilyl ligands. 
(C) American Chemical Society, J. Phys. Chem. B, Kim et al, jp048582k Supporting Info Page S16

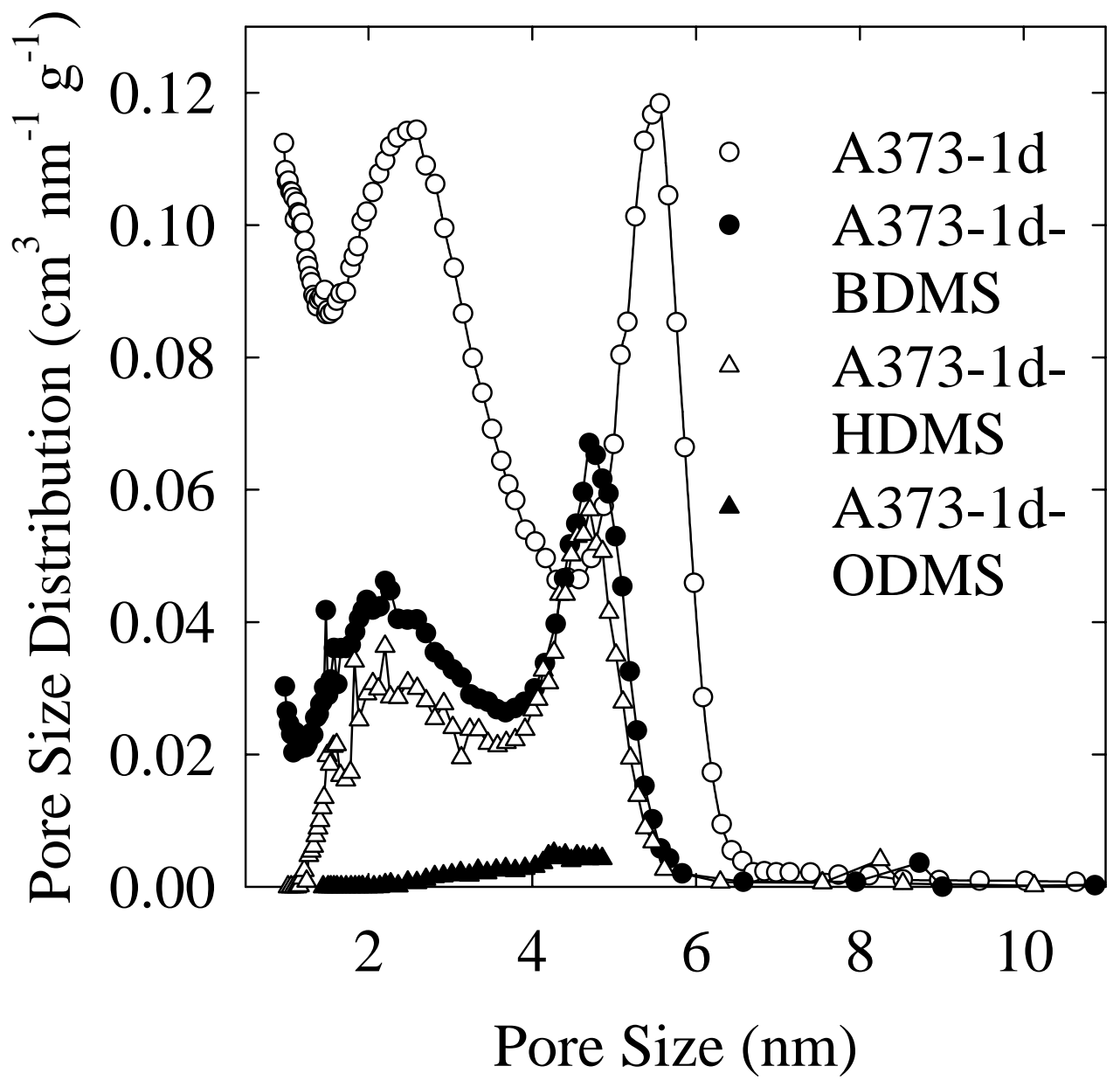

Supporting Figure 15S. Pore size distributions calculated from argon adsorption isotherms for SBA-16 sample A373-1d, unmodified and modified with butyldimethylsilyl, hexyldimethylsilyl and octyldimethylsilyl ligands. 
(C) American Chemical Society, J. Phys. Chem. B, Kim et al, jp048582k Supporting Info Page S17

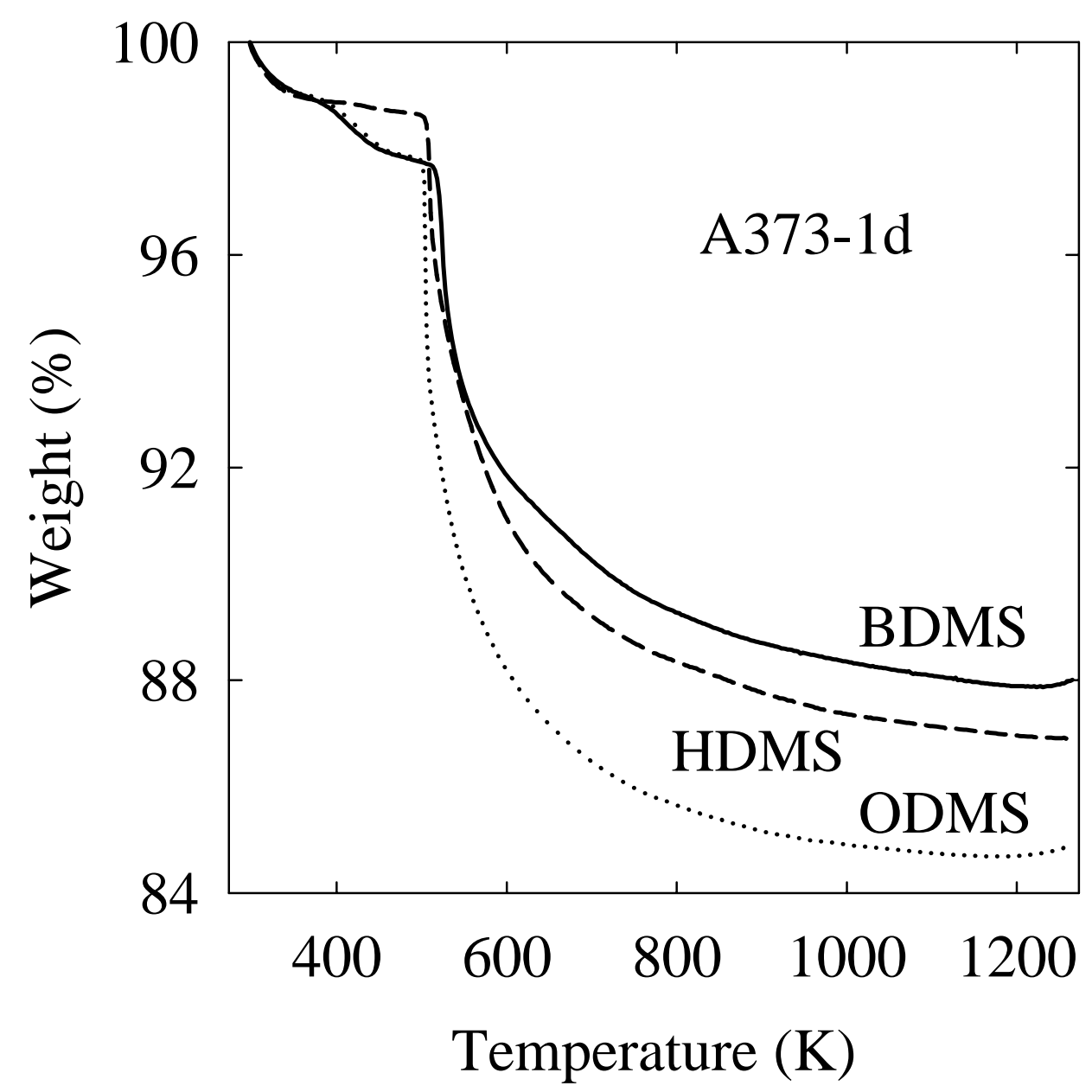

Supporting Figure 16S. Weight change curves recorded under air atmosphere for SBA-16 sample A373-1d modified with butyldimethylsilyl, hexyldimethylsilyl and octyldimethylsilyl ligands. 
(c) American Chemical Society, J. Phys. Chem. B, Kim et al, jp048582k Supporting Info Page S18

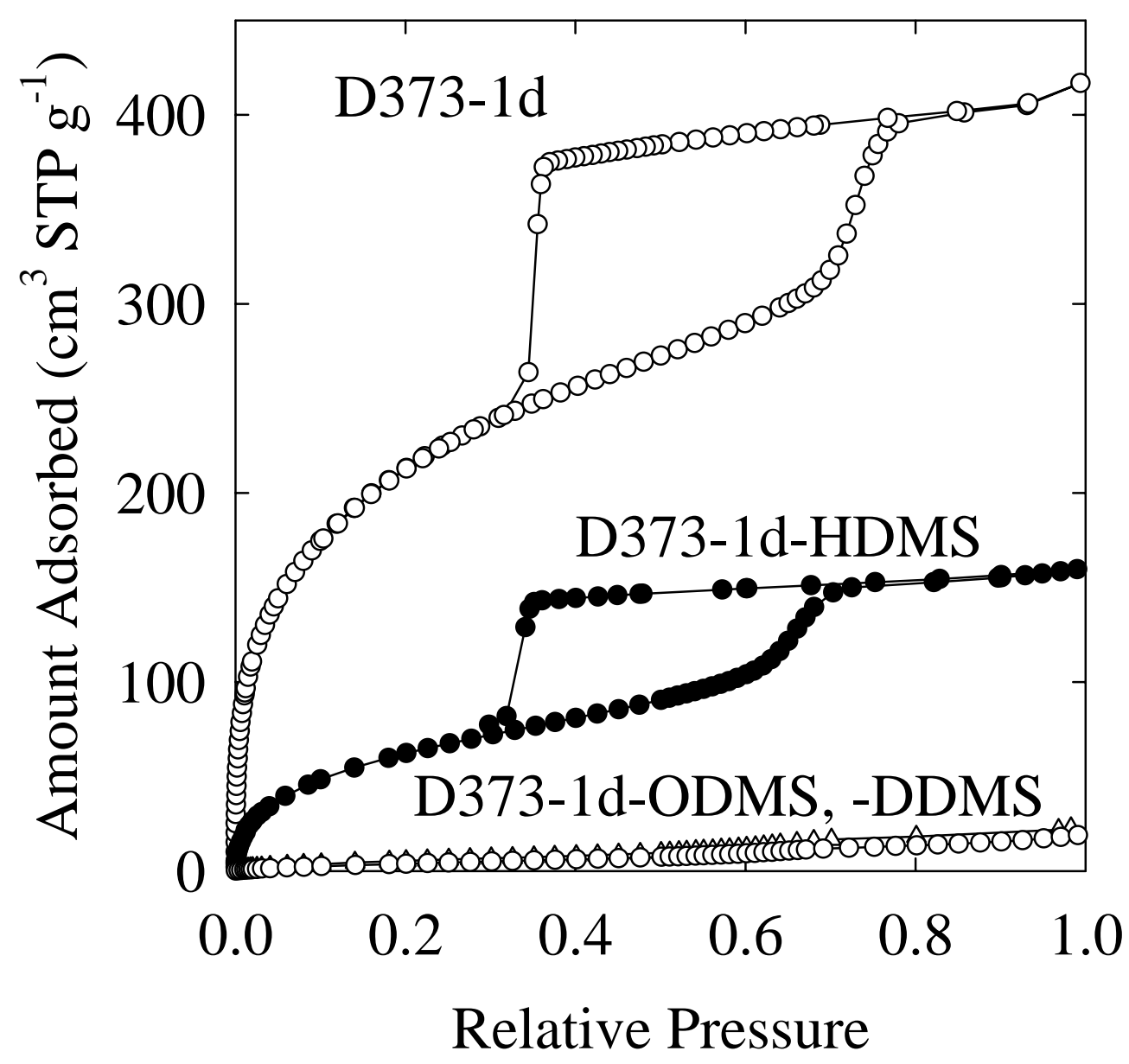

Supporting Figure 17S. Argon adsorption isotherms for SBA-16 sample D373-1d, unmodified and modified with hexyldimethylsilyl, octyldimethylsilyl and decyldimethylsilyl ligands. 
(C) American Chemical Society, J. Phys. Chem. B, Kim et al, jp048582k Supporting Info Page S19

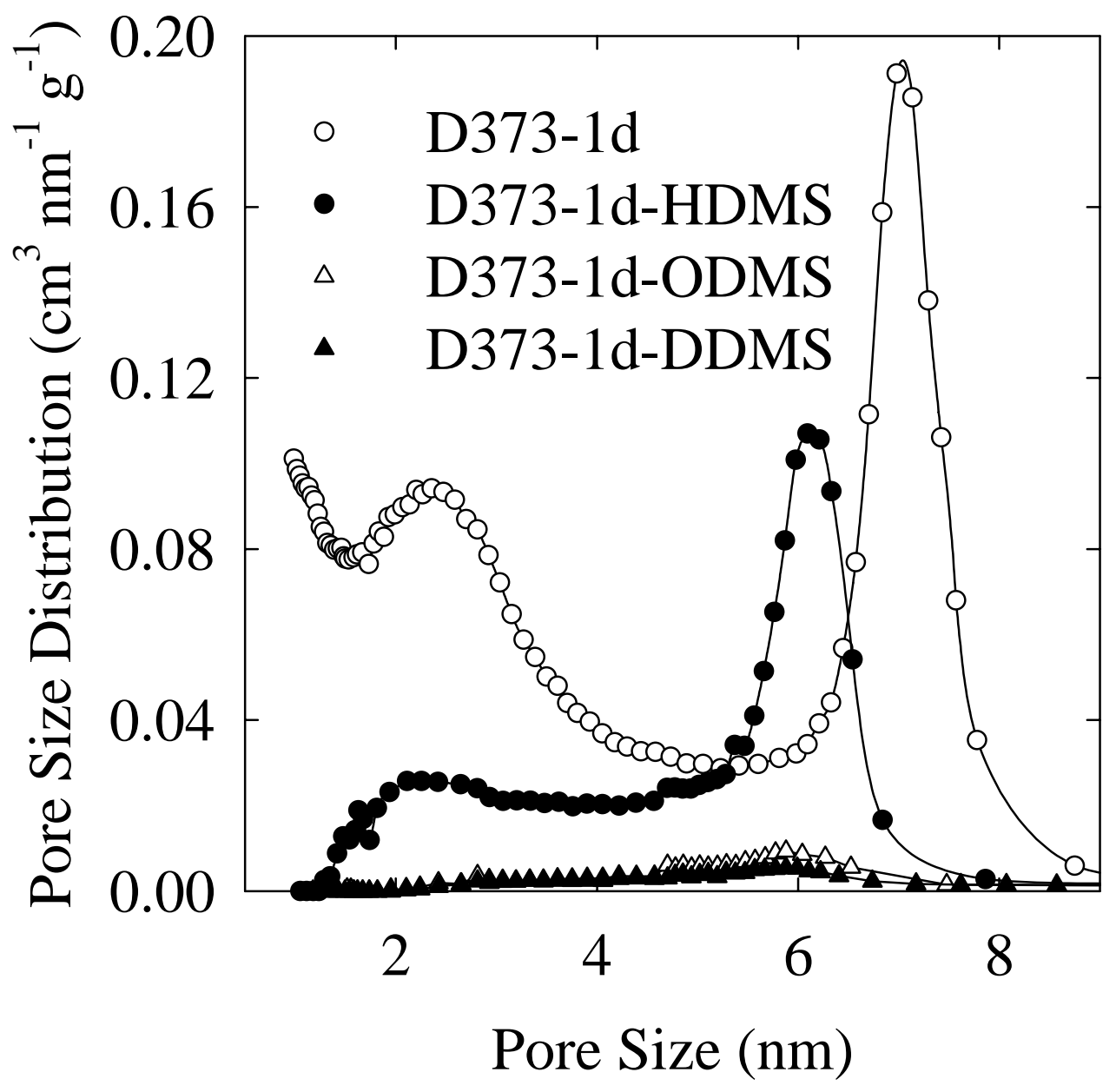

Supporting Figure 18S. Pore size distributions calculated from argon adsorption isotherms for SBA-16 sample D373-1d, unmodified and modified with hexyldimethylsilyl, octyldimethylsilyl and decyldimethylsilyl ligands. 
(C) American Chemical Society, J. Phys. Chem. B, Kim et al, jp048582k Supporting Info Page S20

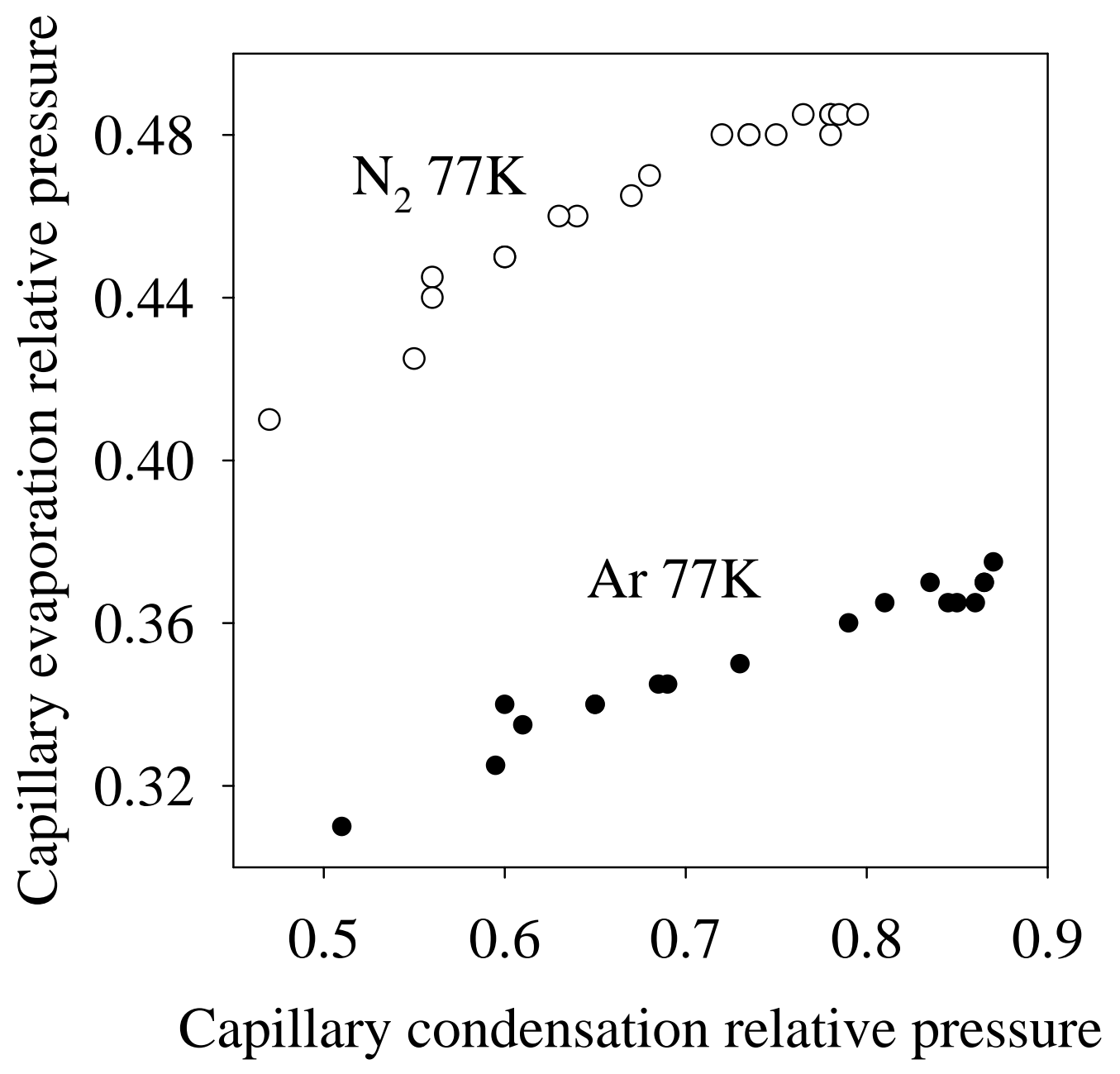

Supporting Figure 19S. The relation between the capillary condensation pressure and the pressure of capillary evaporation at the lower limit of adsorption-desorption hysteresis. 